\title{
Automatically Generated Vegetation Density Maps with LiDAR Survey for Orienteering Purpose
}

\author{
Dušan Petrovič ${ }^{\mathrm{a}}$ \\ ${ }^{a}$ University of Ljubljana, Faculty of Civil and Geodetic Engineering, Ljubljana, Slovenia; dusan.petrovic@fgg.uni-lj.si
}

\begin{abstract}
The focus of our research was to automatically generate the most adequate vegetation density maps for orienteering purpose. Application Karttapullatuin was used for automated generation of vegetation density maps, which requires LiDAR data to process an automatically generated map. A part of the orienteering map in the area of KazljeTomaj was used to compare the graphical display of vegetation density. With different settings of parameters in the Karttapullautin application we changed the way how vegetation density of automatically generated map was presented, and tried to match it as much as possible with the orienteering map of Kazlje-Tomaj. Comparing more created maps of vegetation density the most suitable parameter settings to automatically generate maps on other areas were proposed, too.
\end{abstract}

Keywords: Orienteering map, LiDAR data, Vegetation map, Application Karttapullatuin

\section{Introduction}

Orienteering maps, maps for orienteering sport, are the most standardized type of the maps (Zentai, 2000), defined by International Specification for orienteering Maps (ISOM). Standardization is essential to assure equal and fair conditions for all competitors. It is also very important, that the maps are regularly updated, showing the actual situation on the field. Maps are very detailed and present landscape at large scale, which allows competitor to estimate the time needed to move along the course. Besides the other criteria influencing speed, like steepness, ground roughness, physical built obstacles, etc. vegetation is probably the one causing the highest running speed reduction. That's also the reason, why vegetation is one of the most important elements of orienteering map; there are even 22 of all 121 symbols and two different colors of all together five used for vegetation features: green, yellow and additionally also white, uncolored areas, which also shows the clear, fast runnable forest area. Figure 1 shows different vegetation areas and objects on two inserts of orienteering map.
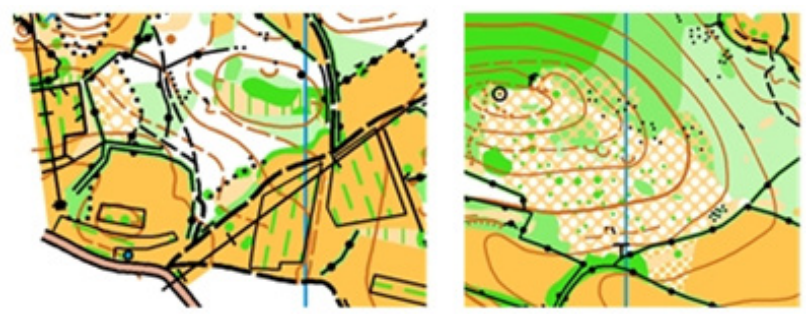

Fig. 1. Different symbols for vegetation on Orienteering map (maps by Ivan Nagy)

On the other hand, there are many problems of presenting vegetation on orienteering maps: lack of useful databases and other sources of data (comparing to other content, like buildings, roads), vegetation type and density changes in small areas and in short period and finally, interpretation of the density, height and type of vegetation and their influence on run speed reduction. Such interpretation in most cases can be done only by the experienced map maker, former orienteering runner in most cases; on the terrain only.

\section{LiDAR data as the source for vegetation density map}

LiDAR technology was recognized as very useful as the main source data for creating orienteering and also topographic maps (Ditz et al, 2014, Petrovič 2010, 2011, Petrovič and Podobnikar 2011). The LiDAR point cloud as the basic result of laser scanning includes reflections of different terrain objects, from ground, built objects, and also grass, leaves, branches and other parts of vegetation (Figure 2). The resolution of cloud points can be very high and therefore representation of the terrain with all objects on it may be quite detailed.

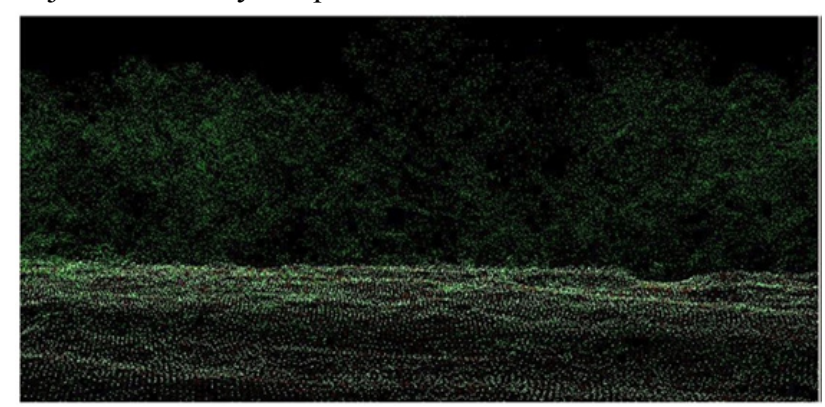

Fig. 2. Point cloud shows different types of vegetation, grassland, bushes, and trees

Such point cloud is probably the best possible source data for orienteering map maker to get the feeling about the density and sometimes even the type of vegetation, even better than camera movie, which shows only two dimensional, flat images. From point cloud map maker have to estimate the run speed reduction due to the vegetation height, density and type. Different sets of classification, using intensity, order of return, and height above ground etc. can support him to understand and recognize complex vegetation appearance. But even from those classified data to vegetation content on the orienteering map there is still intensive manual work. 
Some applications try to automatize the process of interpretation for different content from lidar point clouds, where exact purpose of derived data has to be predefined. Orienteering maps with global standardizations are quite appropriate for that. One such freely available application Karttapullautin can be used for automatic creation of orienteering maps with all content. Maps are not perfect, but good enough for trainings or small local events (Petrovič 2013, 2014). One of the strength of the application is the parameter tuning possibility; every map creator can adjust number of parameters according to his specifics: density and complexity of lidar point cloud data, type of the terrain, including type and density of vegetation, type of ground (rocky, sandy, moody) etc. More than 30 parameters can be adjusted for vegetation presentation only and all of them partly influence the final result.

\section{Automatically created vegetation areas for orienteering map reparation in electronic form}

The aim of our research was therefore finding the optimal set of parameters for selected specific area (Cerar, 2016) using application Karttapullautin. As a reference we used the existing orienteering map, made by experienced map maker, who mapped the vegetation based on field check. The whole methodology based on iterative tuning sets of parameters with comparing results to reference after each step. The success of result was calculated with the overlapping ratio of the same and neighboring category between reference and the result. ISOM defines 13 different areal types of vegetation: from open (grass) land to impassable dense vegetation area, from pure natural to planted cultivated area. In our research we focused on five most important for the runner:

1)open land (full yellow),

2)open runnable forest (white),

3)forest that enables slow running (light green),

4)forest where running is difficult (middle green) and

5)impassable forest or other vegetation (dark green).

Automatically created vegetation map was compared with the reference map, we measured the areas on both maps covered with the same category and marked them as a full coverage (F). But usability of the presented vegetation can't be estimated only with an exact overlapping. Sometimes it is very difficult to differ between neighbor categories on the terrain, but middle green would give the similar information to the runner as dark green, although not the same. Therefore we decided to count also the areas overlapping with neighboring category $(\mathrm{N})$, but weighted. The final usability $(\mathrm{U})$ of the vegetation on the map was therefore calculated as:

$\mathrm{U}=(\mathrm{F}+0,65 \times \mathrm{N}) / 10$,

where $\mathrm{F}$ is \% of exact overlaping of the category in the selected area (Full coverage) and $\mathrm{N}$ is \% of overlapping neighboring category, as presented in Figure 3

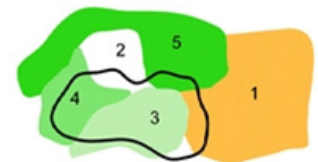

(1) open land (full yellow)

(2) open runnable forest (white)

(3) forest enables slow running (light green)

(5) forest where running is difficult (middle green) and

$\bigcirc$ automatically created (3) light green

Fig. 3. Calculation of the usability of vegetation map

\subsection{Case Area}

Area in Karst region in Slovenia was used as a case area. Karst area is very popular for orienteering in Slovenia,

karstic plateau with complex relief formations (depressions, pits, ditches), stony ground and objects (boulders, rock faces, stone walls) and diverse vegetation attracts athletes from many European countries for trainings and competitions. Due to mild climate running is possible from early spring to late autumn, usually also in winter, when lot of other terrains in central Europe are not suitable for orienteering. Therefore a lot of maps that are regular updated exist on the area and one of those maps, Kazlje - Tomaj (Fig. 4) was used as a reference in our research.

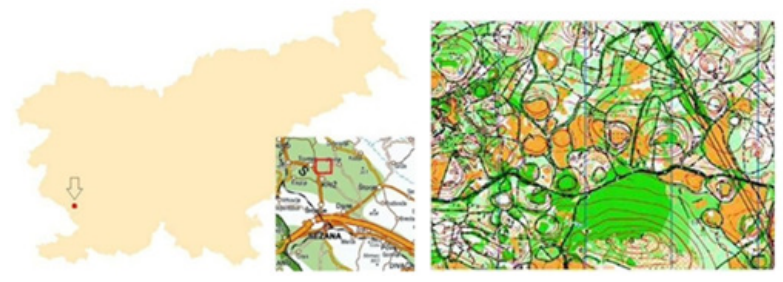

Fig. 4. Case area in Karst region in Slovenia, reference map Kazlje - Tomaj (map by Ivan Nagy)

\subsection{Used Data}

Slovenia is one of the rare countries, where whole territory is covered with high density laser scanning data and where all the data is freely available. The project of LiDAR scanning of Slovenia started in 2011 as a part of flood protection measures. Partly in 2011, but mostly in 2014 and 2015 whole territory was surveyed with density 5 points / sq. m. Web service at National Agency for the Environment offer users data in different formats (classified point cloud, point cloud of ground points and 1 $\times 1 \mathrm{~m} \mathrm{DTM}$ ) in two different coordinate systems (Fig 5).

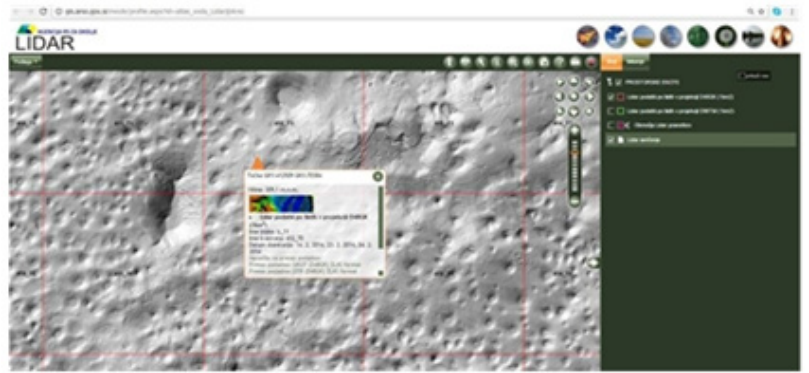

Fig. 5. Web service with LiDAR data for Slovenia (http://gis.arso.gov.si/evode/) 
Data is available in 1 sq. $\mathrm{km}$ blocks, for our research we needed complete point cloud with ground and other points, too.

\subsection{Case study}

Kartapullautin is free application for noncommercial use or if used for navigation sport mapping (orienteering, rogaining, adventure racing map making), created by Finnish author Jarkko Ryyppo (http://www.routegadget.net/karttapullautin/). It can be used for generating orienteering training maps without field checking. In our research we used version 20150426; the latest version 20160405 was issued just in the time of our research. Point cloud LAS data is used as a source data while the final result is image of complete orienteering map, composed of partly created vector data (contours, point objects) and set of raster images (buildings, water areas, vegetation). Vegetation mask as one separate raster layer can therefore be analyzed separately from other content. 39 parameters that can be adjusted by user in Kartapullautin and influence on final vegetation mark image are introduced in Table 1 with initial predefined values.

\begin{tabular}{|c|c|}
\hline greenground & 0.8 \\
\hline zone1 & $0.5|4| 99 \mid 1$ \\
\hline zone2 & $4|7| 10.0 \mid 0.4$ \\
\hline threshold1 & $0.20|2.0| 0.45$ \\
\hline threshold2 & $2.0|6| 0.41$ \\
\hline threshold3 & $6|16| 0.42$ \\
\hline threshold4 & $16|20| 0.46$ \\
\hline threshold5 & $20|99| 0.47$ \\
\hline pointvolumefactor & 0.35 \\
\hline firstandlastreturnfactor & 0.1 \\
\hline lastreturnfactor & 0.2 \\
\hline greenshades & $0.4|0.8| 1.3|2.6| 99$ \\
\hline lightgreentone & 230 \\
\hline greendetectsize & 3 \\
\hline groundboxsize & 3 \\
\hline medianboxsize & 12 \\
\hline medianboxsize2 & 1 \\
\hline yellowheight & 0,8 \\
\hline yellowthresold & 0,89 \\
\hline
\end{tabular}

Table 1. Parameters for vegetation mask in Kartapullautin

Greenshades define range of different used green colors, from light to dark green. Threshold 1 - 5 parameters are used for balancing tall and low forest. Very low vegetation mostly influence the run speed, middle one visibility,

while tall vegetation only define type of the forest. Zone 1 and 2 parameters are used for separating different types of forest trees, according to density of lover branches. The other parameters are used to divide areas between open,

semi open, rough and forest areas and to determine the smallest area that is presented as a separate area. Too small

recognized and presented areas would lead to extremely scattered and therefore poorly readable map.

Using initially set parameters we created the first version of automatically generated vegetation mask map and compered it with the reference map (Fig. 6).

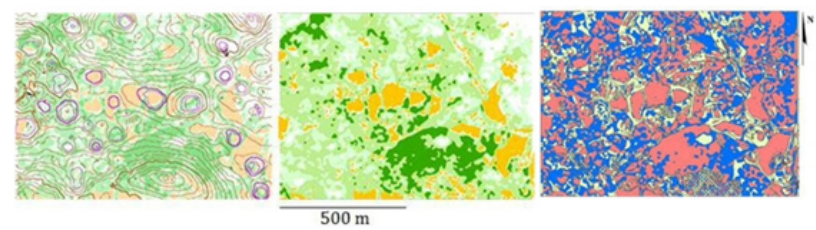

Fig. 6. Automatically generated vegetation mask; reference map; overlapping analyze (pink shows full coverages areas and blue overlapping neighboring category) (Cerar, 2016)

Calculation according to presented methodology gave results presented in Table 2 .

\begin{tabular}{|c|c|c|c|c|}
\hline & $\begin{array}{l}\text { area on } \\
\text { autom. } \\
\text { gener. } \\
\text { map (sq. } \\
\mathrm{m} \text { ) } \\
\end{array}$ & $\begin{array}{l}\text { (F) } \% \\
\text { of } \\
\text { exact } \\
\text { overlap }\end{array}$ & $\begin{array}{l}(\mathrm{N}) \% \text { of } \\
\text { overlapping } \\
\text { neighbouring } \\
\text { category }\end{array}$ & $\begin{array}{l}\text { (U) } \\
\text { usability }\end{array}$ \\
\hline $\begin{array}{l}\text { (1) open land } \\
\text { (full yellow), }\end{array}$ & 89634,52 & 83,62 & 7,60 & 8,86 \\
\hline $\begin{array}{l}\text { (2) open } \\
\text { runnable forest } \\
\text { (white), }\end{array}$ & 69953,79 & 51,16 & 39,54 & 7,69 \\
\hline $\begin{array}{l}\text { (3) forest } \\
\text { enables slow } \\
\text { running (light } \\
\text { green), }\end{array}$ & 181995,55 & 28,02 & 45,58 & 5,76 \\
\hline $\begin{array}{l}\text { (4) forest where } \\
\text { running is } \\
\text { difficult (middle } \\
\text { green) and }\end{array}$ & 282444,97 & 22,79 & 43,27 & 5,09 \\
\hline $\begin{array}{l}\text { (5) impassable } \\
\text { forest or other } \\
\text { vegetation } \\
\text { (dark green). }\end{array}$ & 90375,01 & 48,51 & 27,54 & 6,64 \\
\hline not classified & 11276,16 & & & \\
\hline sum & 725680,00 & 38,02 & 37,26 & 6,22 \\
\hline average & 142880,77 & 46,82 & 32,71 & 6,81 \\
\hline
\end{tabular}

Table 2 . Results of analyze using initial parameters 
Initial values of parameters gave partly satisfied results but our goal was to see, how far usability of the vegetation mask map can be improved with adjusting parameters. The iterative procedure was used, starting with the first group of parameters, continuing with next ones. Figure 7 shows influence of adjusting parameter "greenshades" on final vegetation mask map.

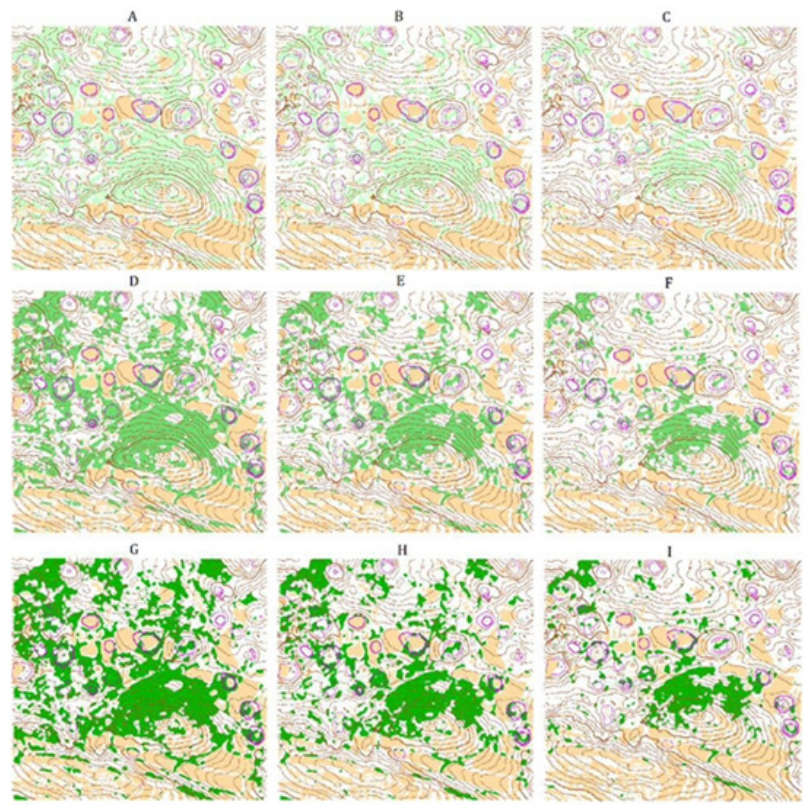

Fig. 7. Influence of adjusting parameter "greenshades" on vegetation mask map (Cerar, 2016)

After 4 complete iterations where in each most of parameters were adjusted we managed to improve the overall usability in $9 \%$ for entire area and in $2 \%$ only in average of all vegetation categories, as presented in Table 3. Figure 8 shows the overlapping map after fourth iteration and Table 4 the final values for parameters.

\begin{tabular}{|l|c|c|c|c|}
\hline & $\begin{array}{l}\text { area on } \\
\text { autom. } \\
\text { gener. map } \\
\text { (sq. } \mathrm{m} \text { ) }\end{array}$ & $\begin{array}{l}\text { (F) \% } \\
\text { of } \\
\text { exact } \\
\text { overlap }\end{array}$ & $\begin{array}{l}\text { (N) \% of } \\
\text { overlapping } \\
\text { neighbouring } \\
\text { category }\end{array}$ & $\begin{array}{l}\text { (U) } \\
\text { usability }\end{array}$ \\
\hline $\begin{array}{l}\text { (1) open } \\
\text { land (full } \\
\text { yellow), }\end{array}$ & 90224,79 & 83,08 & 7,48 & 8,79 \\
\hline $\begin{array}{l}\text { (2) open } \\
\text { runnable } \\
\text { forest } \\
\text { (white), }\end{array}$ & 203059,09 & 40,83 & 45,79 & 7,06 \\
\hline $\begin{array}{l}\text { (3) forest } \\
\text { enables slow } \\
\text { running } \\
\text { (light green), }\end{array}$ & 209971,89 & 30,88 & 44,88 & 6,01 \\
\hline $\begin{array}{l}\text { (4) forest } \\
\text { where } \\
\text { running is } \\
\text { difficult } \\
\text { (middle } \\
\text { green) and }\end{array}$ & 120367,90 & 30,02 & 46,63 & 6,03 \\
\hline
\end{tabular}

\begin{tabular}{|c|c|c|c|c|}
\hline $\begin{array}{l}\text { (5) } \\
\text { impassable } \\
\text { forest or } \\
\text { other } \\
\text { vegetation } \\
\text { (dark green). }\end{array}$ & 92056,32 & 50,80 & 27,67 & 6,88 \\
\hline not classified & 10000,01 & & & \\
\hline sum & 725680,00 & 42,70 & 38,50 & 6,77 \\
\hline average & 143136,00 & 47,12 & 34,49 & 6,95 \\
\hline
\end{tabular}

Table 3. Results of analyze after fourth iteration

\begin{tabular}{l|l}
\hline greenground & 0.8 \\
\hline zone1 & $0.5|4| 99 \mid 1$ \\
\hline zone2 & $4|7| 10.0 \mid 0.4$ \\
\hline threshold1 & $\mathbf{0 . 2 0 | 2 . 5 / 0 . 2 8}$ \\
\hline threshold2 & $\mathbf{2 . 5 / 5 / 0 . 3 7}$ \\
\hline threshold3 & $\mathbf{5 / 8 / 0 . 4 3}$ \\
\hline threshold4 & $\mathbf{8 / 1 2 / 0 . 3 9}$ \\
\hline threshold5 & $\mathbf{1 2 / 9 9 / 0 . 3 7}$ \\
\hline pointvolumefactor & 0.15 \\
\hline firstandlastreturnfactor & 0.1 \\
\hline lastreturnfactor & 0.2 \\
\hline greenshades & $0.64|0.98| 1.37$ \\
\hline lightgreentone & 205 \\
\hline greendetectsize & 3 \\
\hline groundboxsize & 3 \\
\hline medianboxsize & 12 \\
\hline medianboxsize2 & 1 \\
\hline yellowheight & $\mathbf{0 , 8 8}$ \\
\hline yellowthresold & $\mathbf{0 , 8 9}$ \\
\hline
\end{tabular}

Table 4. Final values of parameters for vegetation mask in Kartapullautin
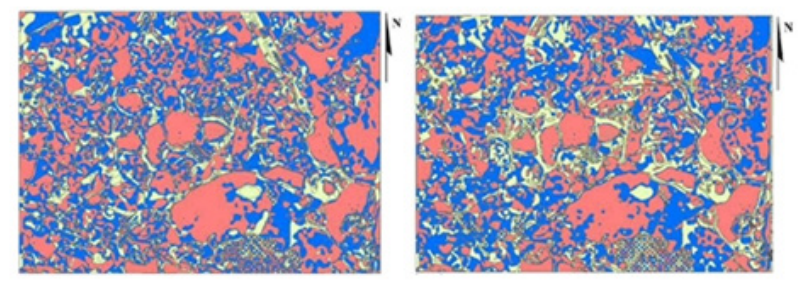

Fig. 8. Overlapping analyze with initial and final values of parameters (pink shows full coverages areas and blue overlapping neighboring category) (Cerar, 2016) 


\subsection{Title and abstract}

Although adjustments of parameters only slightly improved the results compared with initial parameters we tried to verify, what happens in other areas. Since all adjustments were done for karstic area we select another area in Karts plateau, few $\mathrm{km}$ from initial case area. Results are presented in Fig. 9 and Table 5.

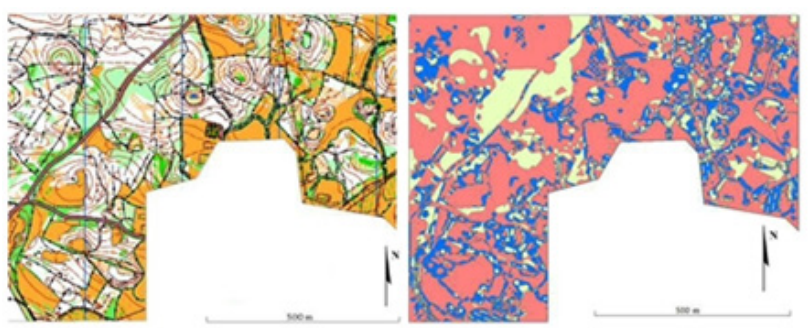

Fig. 9. Reference orienteering map for area 2 and overlapping analyze with final values of parameters (pink shows full coverages areas and blue overlapping neighboring category) (Cerar, 2016)

\begin{tabular}{|l|c|c|}
\hline & $\begin{array}{l}\text { (U) } \\
\text { usability } \\
\text { in area 1 }\end{array}$ & $\begin{array}{l}\text { (U) } \\
\text { usability } \\
\text { in area 2 }\end{array}$ \\
\hline $\begin{array}{l}\text { (1) open land (full } \\
\text { yellow), }\end{array}$ & 8,79 & 9,39 \\
\hline $\begin{array}{l}\text { (2) open runnable forest } \\
\text { (white), }\end{array}$ & 7,06 & 7,03 \\
\hline $\begin{array}{l}\text { (3) forest enables slow } \\
\text { running (light green), }\end{array}$ & 6 & 5,8 \\
\hline $\begin{array}{l}\text { (4) forest where running } \\
\text { is difficult (middle green) } \\
\text { and }\end{array}$ & 6,03 & 2,98 \\
\hline $\begin{array}{l}\text { (5) impassable forest or } \\
\text { other vegetation (dark } \\
\text { green). }\end{array}$ & 6,88 & 3,96 \\
\hline \\
whole map
\end{tabular}

Table 5. Usability of vegetation mask map in area 1 and 2

\section{Conclusions}

The final test in area 2 showed even better results of overlapping vegetation areas as in the area, where parameters were adjusted. This might point out that adjustment in the first test area wasn't optimal, while different vegetation combination might also be a reason for such result. Further on, another two tests with same parameters were made in two completely different areas with different vegetation, where results were significantly worse, as expected. More tests using different methods and different applications should be done before finding optimal solution for creating vegetation map mask for orienteering maps.

\section{Acknowledgements}

The article bases on results of thesis Automatically Generated Vegetation Density Maps with Lidar Survey for Orienteering Purpose by Gašper Cerar, supervised by the author and by Blaž Repe, Ph.D. from University of Ljubljana, Faculty of Arts. The existing orienteering maps used for comparing results were kindly offered by Ivan Nagy.

\section{References}

Automated Orienteering Map Generation Experience. URL:

https://dl.dropboxusercontent.com/u/5544745/pullautin/i ndex.html. Accessed 12. 7. 2016.

Cerar, G. (2016). Samodejno izdelovanje kart gostote vegetacije $\mathrm{s}$ pomočjo LiDAR-skega snemanja za potrebe orientacijskega teka: diplomsko delo [online]. University of Ljubljana, Faculty of Arts. [Accessed 1 March 2017]. Retrieved from: http://geo.ff.unilj.si/pisnadela/pdfs/dipl_201609_gasper_cerar.pdf).

Ditz, R., Glaner, F., Gartner, G. (2014). Laser scanning and orienteering maps. Scientific journal of orienteering, 19, 1, pg. 13-18. URL: http://orienteering.org/wp-

content/uploads/2010/12/Scientific Journal Of Oriente ering_2014_vol19_1.pdf. Accessed 15.3.2016.

International Orienteering Federation. URL: http://orienteering.org/. Accessed 15. 3. 2016.

International Specification for Orienteering Maps, (2000). Zentai, L. (ur). Radiokatu, Internaional orienteering federation, $34 \mathrm{pg}$.

Karttapullautin, 2013. Karttapullautin vegetation mapping guide. URL: http://www.routegadget.net/karttapullautin/download1.p hp. Accessed 10. 5. 2016.

Petrovič, D. (2010). Some contributions to deriving topographic features from airborne laser scanning data. Geographia Technica, Special issue, pg. 104-110.

Petrovič, D. (2011). Some experiences in making orienteering maps in Slovenia from airborne laser scanning data. Proceedings of the 25th International cartographic conference. Pariz, 3-8 julij 2011, International Cartographic Association. URL:

http://icaci.org/files/documents/ICC proceedings/ICC2 011/Oral\%20Presentations\%20PDF/A3-

Thematic\%20maps, $\% 20$ orienteering\%20map/CO011.pdf. Accessed 13. 3. 2016.

Petrovič, D. (2013). Automation in Orienteering Map Production - Fiction or Reality. Proceedings of the 26th International cartographic conference. Dresden, 25-30 August 2013, International Cartographic Association. URL:http://icaci.org/files/documents/ICC_proceedings/I CC2013/_extendedAbstract/372_proceeding.pdf.

Accessed 13. 3. 2016.

Petrovič, D. (2014). Reducing field work with automation in orienteering map production. Scientific journal of orienteering, $19, \quad 1, \quad$ pg. 3-12. URL: $\quad$ http://orienteering.org/wpcontent/uploads/2010/12/Scientific_Journal_Of_Oriente ering_2014_vol19_1.pdf. Accessed 13.3.2016. 
Petrovič, D., Podobnikar, T., (2011). Use of airborne laser scanning data for updating topographic maps in hilly and mountain areas. Proceedings of the 25 th International cartographic conference. Pariz, 3-8 julij 2011, International Cartographic Association. URL:

http://icaci.org/files/documents/ICC_proceedings/ICC2 011/Oral\%20Presentations\%20PDF/A4-

Mountain\%20cartography/CO-042.pdf . Accessed 13. 3. 2016 . 